\title{
Expectorant Action of Bromhexine in Chronic Obstructive Bronchitis
}

\author{
W. F. D. HAMILTON, ${ }^{*}$ M.B., CH.B.; K. N. V. PALMER, $†$ M.D., F.R.C.P.; M. GENT, $\ddagger$ M.SC.
}

British Medical Fournal, 1970, 3, 260-261

\begin{abstract}
Cummary: Bromhexine was compared with a placebo $\checkmark$ in a double-blind clinical trial in bronchitic inpatients with mucoid sputum. Oral bromhexine $16 \mathrm{mg}$. thrice daily for 11 days compared with placebo resulted in a significant increase in sputum volume and significant decrease in sputum viscosity, and changed markedly the rheological characteristics of the sputum. There was, however, no improvement in ventilatory capacity or in the overall respiratory state as assessed by the patients themselves or their clinician. No patient having the drug had side-effects and there was no change in laboratory findings attributable to it.
\end{abstract}

\section{Introduction}

Bromhexine is a synthetic derivative of vasicine, an alkaloid derived from a plant. Abhatoda vasica, which when taken by mouth has been shown to increase the volume and reduce the viscosity of bronchial secretion in animals, most likely by depolymerization of the high-molecular-weight mucopolysaccharide-protein fibres (Engelhorn and Puschmann, 1963; Boyd and Sheppard, 1966). Controlled clinical trials in chronic bronchitic subjects in this country have yielded conflicting results. Thus, while Gent et al. (1969) found in a double-blind clinical trial that significantly more patients improved in ventilatory capacity when taking bromhexine, $8 \mathrm{mg}$. thrice daily by mouth, than with a placebo, Langlands (1970), again in a double-blind trial using the same dose in bronchitic patients, was unable to find any significant change in sputum volume, viscosity, or ventilatory capacity. In a pilot study we, too, were unable to find any significant change in these measurements in chronic bronchitics given the same dose; but later we were able to show expectorant properties of the drug in higher dosage. We report here the result of a double-blind between-patient study of the effect of bromhexine in a dose of $16 \mathrm{mg}$. thrice daily in bronchitic patients.

\section{Patients and Methods}

Twenty-five inpatients recovering from an exacerbation of chronic bronchitis with mucoid sputum were admitted to the trial. They were adults of both sexes, their mean age was $53.2 \pm 8.9$ years, and they all were or had been heavy cigarette smokers. They took either bromhexine $16 \mathrm{mg}$. thrice daily or identical placebo tablets by mouth for 11 days according to a double-blind randomization scheme. Neither the patients nor the investigators knew whether active or control tablets were being taken. Any other treatment was continued except for cough suppressants and expectorants.

Various measurements were made on the day before the trial started, daily during the trial period, and on the fourth day after treatment was stopped. Daily sputum volumes (ml.) were measured and daily rheological measurements were made in duplicate on specimens of sputum by the same

\footnotetext{
* Research Assistant, Department of Medicine, University of Aber-

t Reader in Medicine, Department of Medicine, University of Aber-

¥ Associate Professor, Department of Applied Mathematics and Clinical Epidemiology and Biostatistics, McMaster University, Hamilton, Ontario.
}

observer. For this purpose a continuous shear method with a Ferranti-Shirley cone and plate viscometer and continuous recorder was used (Palmer et al., 1970). From the rheograms obtained the apparent viscosity (centipoise) at a shear rate of 900 seconds $^{-1}$ and the initial and terminal yield values (dynes/sq. cm.) were calculated. Forced expiratory spirograms were obtained at the beginning and end of the trial, and the forced vital capacity (F.V.C.), the forced expiratory volume in 1 second (F.E.V.1), and the F.E.V. 1 as a percentage of the F.V.C. (F.E.V.1\%) were calculated. The F.E.V.1 and F.V.C. are expressed as a percentage of predicted normal value to allow for differences in age, sex, and height. Before and at the end of the trial the patients were examined by the same observer, and a final assessment was made at the end of the trial by patient and clinician whether the respiratory disability was overall better, the same, or worse.

Estimations of haemoglobin, white cell count, serum aspartate aminotransferase (S.G.O.T.), alkaline phosphatase, serum urea, and urine analysis were carried out at the beginning and end of the trial.

\section{Results}

Twenty-two patients completed the trial-12 received bromhexine and 10 placebo.

Sputum Volume.-The mean daily sputum volumes are shown in Table I. It can be seen that these are much higher on the whole, especially after the third day, for those on bromhexine. During the actual treatment period the mean daily volumes were $25.3 \mathrm{ml}$. for those on the drug and 13.3 $\mathrm{ml}$. for those on placebo. This difference of $12.0 \mathrm{ml}$. is significant $(P<0.01)$, and since the patients were allocated to treatment groups at random the increase seems most likely to be due to the drug.

Rheological Measurements.-The change in apparent viscosity at a shear rate of 900 seconds $^{-1}$ is given in Table II. It is shown as a percentage change and expressed as the logarithm of the value, so the table shows geometric mean viscosities. The mean viscosity level was much lower for those having the drug than for those having placebo, the mean viscosities being 42 and 72 respectively. Since the baseline and post-survey figures are similar for both groups it is reasonable to deduce that the drug had produced the reduction in viscosity. If the observed reduction in viscosity during treatment is compared with the baseline and post-survey results there is an overall mean reduction in viscosity of $39 \%$ compared with an increase of $7 \%$ for the placebo group-a difference which is significant $(P<0.01)$. The absolute change in initial and terminal yield values for the two groups is shown in Table III. The mean reduction of initial yield value for the bromhexine group was 182 dynes/sq. $\mathrm{cm}$., compared with 4 dynes/sq. $\mathrm{cm}$. for those on placebo. This reduction is significant $(\mathrm{P}<0.01)$. Likewise for terminal yield value there was a mean reduction of 3.83 dynes/sq. $\mathrm{cm}$. for those on the drug compared with a mean increase of 8.8 dynes $/ \mathrm{sq}$. $\mathrm{cm}$. for those on placebo. This difference is also significant $(P<0.01)$.

Spirometry.-The results of spirometry at the beginning and end of the treatment period are given in Table IV. Both groups of patients showed slight improvement in mean $\%$ predicted F.E.V.1 and F.V.C. and F.E.V.1\%, but the difference between the groups in none of these measurements is significant statistically. 
TABLE I.-Mean Daily Sputum Volume (ml.)

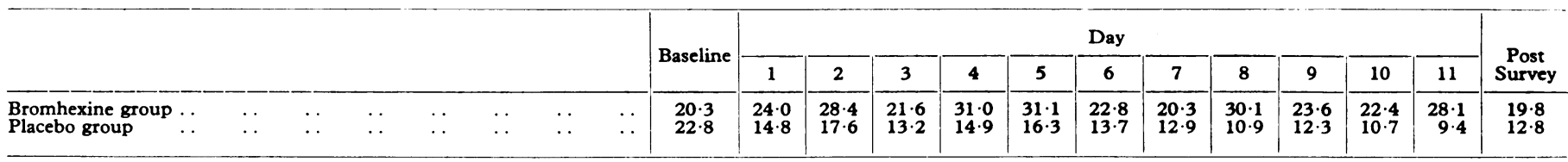

TABLE II.-Geometric Mean Apparent Viscosity of Sputum at Shear Rate of 900 seconds $^{-1}$

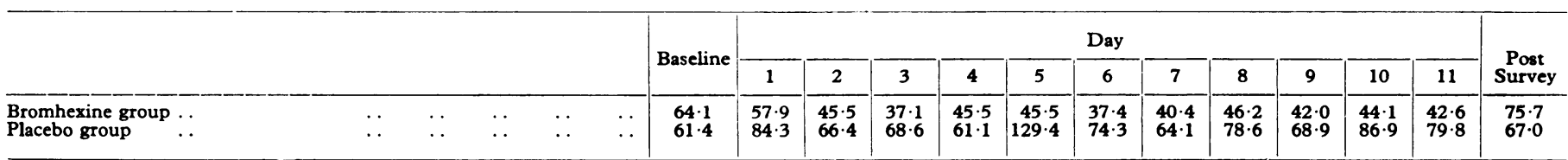

TABLE III.-Absolute Change in Initial and Terminal Yield Values (Dynes/sq. cm.)

\begin{tabular}{|c|c|c|c|c|c|c|c|}
\hline \multicolumn{4}{|c|}{ Initial Yield Value } & \multicolumn{4}{|c|}{ Terminal Yield Value } \\
\hline \multicolumn{2}{|c|}{ Bromhexine } & \multicolumn{2}{|c|}{ Placebo } & \multicolumn{2}{|c|}{ Bromhexine } & \multicolumn{2}{|c|}{ Placebo } \\
\hline Case No. & Change & Case No. & Change & Case No. & Change & Case No. & Change \\
\hline 2 & -89 & 1 & +125 & 2 & & 1 & +21 \\
\hline 3 & -227 & 4 & -109 & 7 & $\begin{array}{l}-33 \\
-8\end{array}$ & $\begin{array}{l}4 \\
5 \\
6\end{array}$ & $\begin{array}{l}-8 \\
+42\end{array}$ \\
\hline $\begin{array}{l}7 \\
8 \\
9\end{array}$ & $\begin{array}{l}-54 \\
-30 \\
-149\end{array}$ & $\begin{array}{r}5 \\
6 \\
10\end{array}$ & $\begin{array}{l}+116 \\
-110 \\
-84\end{array}$ & $\begin{array}{r}8 \\
9 \\
11 \\
12\end{array}$ & $\begin{array}{l}-8 \\
-11 \\
-7 \\
-93\end{array}$ & $\begin{array}{l}10 \\
13\end{array}$ & $\begin{array}{l}+109 \\
+7 \\
+39\end{array}$ \\
\hline $\begin{array}{l}11 \\
12 \\
14\end{array}$ & $\begin{array}{l}-38 \\
-288 \\
-368\end{array}$ & $\begin{array}{l}13 \\
16 \\
17\end{array}$ & $\begin{array}{r}+72 \\
-61 \\
+41\end{array}$ & $\begin{array}{l}14 \\
18 \\
21 \\
22\end{array}$ & $\begin{array}{l}-87 \\
-52 \\
-75 \\
-78\end{array}$ & $\begin{array}{l}16 \\
17 \\
23\end{array}$ & $\begin{array}{l}-65 \\
+29 \\
+4\end{array}$ \\
\hline $\begin{array}{l}18 \\
21 \\
22 \\
25\end{array}$ & $\begin{array}{l}-111 \\
-290 \\
-553 \\
+12\end{array}$ & $\begin{array}{l}23 \\
24\end{array}$ & $\begin{array}{l}+12 \\
-43\end{array}$ & 25 & +13 & 24 & -3 \\
\hline \multicolumn{2}{|c|}{ Mean -182} & \multicolumn{2}{|c|}{ Mean -4} & \multicolumn{2}{|c|}{ Mean $-38 \cdot 3$} & \multicolumn{2}{|c|}{ Mean +8.8} \\
\hline
\end{tabular}

TABLE IV.-Mean F.V.C. and F.E.V. ${ }^{\prime}$ ( $\%$ predicted) and F.E.V.1 \% Before and at the End of the Treatment Period

\begin{tabular}{|c|c|c|c|c|c|c|c|c|}
\hline & \multicolumn{3}{|c|}{ Bromhexine } & \multicolumn{3}{|c|}{ Placebo } \\
\hline & & & Baseline & Final & Change & Baseline & Final & Change \\
\hline $\begin{array}{l}\text { F.V.C. } \\
\text { F.E.V.1 } \\
\text { F.E.V.1 \% }\end{array}$ & $\begin{array}{l}\ldots \\
\cdots \\
\cdots\end{array}$ & $\begin{array}{l}\ldots \\
\cdots \\
\ldots\end{array}$ & $\begin{array}{l}45 \cdot 3 \\
27 \cdot 4 \\
43 \cdot 3\end{array}$ & $\begin{array}{l}51 \cdot 5 \\
32 \cdot 6 \\
45 \cdot 3\end{array}$ & $\begin{array}{l}+6 \cdot 2 \\
+5 \cdot 2 \\
+2.0\end{array}$ & $\begin{array}{l}52 \cdot 0 \\
30 \cdot 1 \\
46 \cdot 8\end{array}$ & $\begin{array}{l}63 \cdot 1 \\
37 \cdot 0 \\
47 \cdot 5\end{array}$ & $\begin{array}{l}+11 \cdot 1 \\
+\quad 7 \cdot 1 \\
+1 \cdot 3\end{array}$ \\
\hline
\end{tabular}

None of the differences between treatment groups for these measurements are statistically significant.

Table V.-Patient and Clinician Assessment

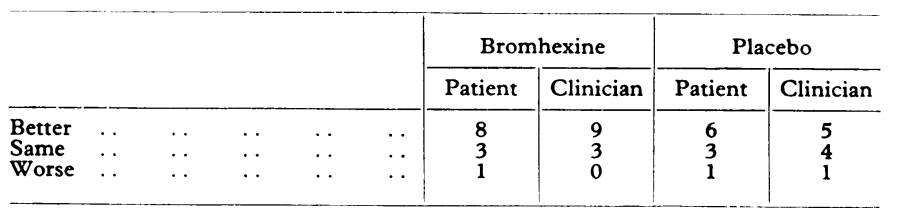

Clinical Assessment.-The final assessment by patient and clinician is shown in Table V. The differences between the two groups are not statistically significant. There was no change in haemoglobin, alkaline phosphatase, serum urea, or urine analysis during the trial. Both groups showed a slight reduction in total white cell count. Two patients on the drug and one on placebo showed minimal rises in S.G.O.T. No patients having the drug complained of side-effects; one patient on placebo experienced nausea.

\section{Discussion}

This double-blind controlled clinical trial shows clearly that in a dose of $16 \mathrm{mg}$. thrice daily bromhexine in bronchitic patients increases sputum volume and reduces its viscosity and yield values. The yield value is the stress that must be applied to the material before flow starts before (initial yield value) and after shearing (terminal yield value). The fact that the drug led to a reduction of both yield values and viscosity indicates that it produces a pronounced change in the rheological properties of the sputum, which is in keeping with the suggestion that it leads to depolymerization of highmolecular-weight mucopolysaccharide fibres in the sputum. The geometric mean post-survey values for viscosity of those who had been receiving the drug was higher than those having placebo, but this difference does not reach significance levels, and it does not, we think, indicate that after a course of bromhexine the sputum viscosity may increase somewhat.

It is perhaps surprising that in spite of an increase in sputum volume and decrease in its viscosity there was no improvement in spirometry, especially as Gent et al. (1969) found improvement in ventilatory function in patients with chronic bronchitis and asthma when given bromhexine in lower dosage than we used. Their patients, however, had milder airway obstruction, and presumably the clearance of the airways of retained secretion reduced airway obstruction. Our patients, on the other hand, had much more severe airway obstruction, which was probably for the most part irreversible owing to structural change in the bronchi, and could not therefore be improved in the same way by removal of secretion. Likewise, there was no overall improvement in respiratory state as assessed by clinician and patient, probably for the same reason.

During the trial no abnormalities were present in laboratory findings apart from a slight fall in total white cell count in both groups reflecting recovery from the initial bacterial infection. The trivial rise in S.G.O.T. in two patients on the drug and one on placebo is probably not significant. It is, however, especially noteworthy that no patients complained of side-effects (the commonest are nausea and heartburn) while on the larger dose of the drug.

As a result of this trial and our subsequent clinical experience with this drug in a wide variety of patients with respiratory disease, where retention of bronchial secretion was a problem, we think it is a valuable therapeutic advance in the difficult problem of aiding expectoration in the respiratory patient.

Our thanks are due to Messrs. Boehringer Ingelheim Ltd. for supplying the drug and placebo and for jupporting the research assistant for one year.

Requests for reprints to: Dr. K. N. V. Palmer, Department of Medicine, Foresterhill, Aberdeen AB9 2ZD.

\section{REFERENCES}

Boyd, E. M., and Sheppard, P. (1966). Archives Internationales Pharmacodynamie et de Therapie, 163, 284.

Engelhorn, R., and Puschmann, S. (1963). Arzneimittel-Forschung, 13, 474.

Gent, M., Knowlson, P. A., and Prime, F. J. (1969). Lancet, 2, 1094.

Langlands, J. (1970). Lancet, 1, 448.

Palmer, K. N. V., Ballantyne, D., Diament, M. L., and Hamilton, W. F. D. (1970). British Fournal of Diseases of the Chest. In press. 